\title{
COWSLIP (PRIMULA VERIS L.) CHEMICAL COMPOSITION DEPENDENCE ON THE SOIL PROPERTIES
}

\begin{abstract}
Aurelija PAULAUSKIENÉ, Department of Agrobiology and Food Sciences, Faculty of Agronomy, Vytautas Magnus University, K. Donelaičio g. 58, LT-44248 Kauno, Lithuania, aurelija.paulauskiene@vdu.lt (corresponding author)

Živilè TARASEVIČIENÉ, Department of Agrobiology and Food Sciences, Faculty of Agronomy, Vytautas Magnus University, K. Donelaičio g. 58, LT-44248 Kauno, Lithuania, zivile.taraseviciene@ vdu.lt

It is known that perennial herbaceous plants growing in harsh conditions in unfertilized soils accumulate large amounts of valuable substances. The aim of the study was to investigate the main chemical composition of wild growth cowslip (Primula veris L.) leaves and inflorescences. Plants samples were collected in April-May of 2019 in different regions of Lithuania (area No. 1 and area No. 2). The plant samples were analysed immediately after harvesting. Dry matter, soluble solids, ascorbic acid content, titratable acidity was determined by standard methods. Total carotenoid content, chlorophyll $a$ and $b$ were analysed by spectrophotometer. The total phenolic content was established by using the Folin-Ciocalteu reagent. The amount of crude ash was determined by the dry burning of samples at a temperature of $500{ }^{\circ} \mathrm{C}$. Phosphorus was measured photometrically, calcium content was established according to Commission Directive. The potassium was determined by flame photometry, magnesium, iron, copper, manganese, zinc, and boron contents were identified by atomic absorption spectrophotometry. The results were analysed by using a two-way analysis of variance. Our research data analysis showed the different chemical compositions of cowslip samples collected from different areas. Higher amounts of dry matter, ascorbic acid, chlorophyll $a$ and $b$, total carotenoids, and total phenolics were found in the plants from area No. 1. In the plants from area No. 2 were established higher content of crude ash. The amounts of mineral elements in plants varied unequally. The correlations showed the dependence of the chemical composition of cowslip aerial parts on the soil composition.
\end{abstract}

Keywords: chemical composition, perennial plants, soil.

\section{INTRODUCTION}

The cowslip (common cowslip, cowslip primrose) (Primulas veris L.) is an herbaceous perennial species of flowering plant in the family Primulaceae. The plant is most common in Western and Central Europe, Southern Scandinavia, the Baltic States, and even Siberia (Guggisberg et al., 2006). The bright yellow flowers start to bloom in spring, forming inflorescences of 10 to 30 blossoms together on a single stem. The cowslip is frequently found on open fields, dry meadows, sloping and rare and dry forests, forest sites (Brys, Jacquemyn, 2009). Hill et al. (2004) pointed out that Primula veris is a characteristic of nutrient-poor habitats. Cowslip plants is common in acidic and neutral ( $\mathrm{pH}$ 5.0-8.0) soils, and tolerates low nitrogen and phosphorus content (Brys, Jacquemyn, 2009).

Cowslip is a well-known medicinal plant with a long history of use (Assessment report ..., 2013, Bączek et al., 2017). Plants flowers and leaves are being used as extract, tincture, and for culinary purposes raw as a salad green. Flowers are of use for making wine, and tea is of special value in strengthening the nerves, relieving insomnia, and as an excellent sedative and antispasmodic remedy (Brys, Jacquemyn, 2009; Assessment report ..., 2013). But the main medicinal raw material is plant roots. Roots are used against coughs, bronchitis, and respiratory tract catarrhs, and also to suppress nervousness, headache, or rheumatism (Bączek et al., 2017). They are collected while the plant is flowering. The roots have a specific odour due to the phenolic aglycones. The main compounds identified in P. veris roots, leaves and flowers are triterpene saponins as well as phenolic compounds, including flavonoids, phenolic acids, and phenolic glycosides (Brys, Jacquemyn, 2009; Bączek et al., 2017). Due to the high content of flavonoids, primrose excels in various biological activities. A significant content of tannins in cowslip defines its astringent, anti-inflammatory, antimicrobial, and antioxidant activity (Shostak et al., 2016). Bączek et al. (2017), El Morchid et al. (2014) established primeverin, primulaverin, catechin, astragalin, chlorogenic acid, rutin, kaempferol, hydroxydimethoxyflavone, quercetin-3-O-dihexoside and some other phenolic compounds. Shostak et al. (2016) determined the highest content of apigenin, scopoletin, and hydroxycinnamic acids present in the leaves of

Copyright (C) 2021 The Authors. Published by Vytautas Magnus University. This is an open-access article distributed under the terms of the Creative Commons Attribution License (CC BY 4.0), which permits unrestricted use, distribution, and reproduction in any medium, provided the original author and source are credited. 
cowslip. The highest content of tannins was established in the rhizomes with roots, which gives the reason to recommend cowslip as the medicinal plant material (Shostak et al., 2016). Scientists stated that the plants flavonoids' qualitative and quantitative composition depends on the plant genotype, developmental stage, and environmental conditions where they grow (Pollastri, Tattini, 2011).

High levels of ascorbic acid are found in aerial parts of cowslip plants. Estonian scientists in fresh cowslip leaves collected from the end of April to the end of June established that the content of ascorbic acid varied from 1.19 to 2.39\% (Meos et al., 2017). They found insignificant higher content of ascorbic acid in plants when flowering was finishing. And even at the end of the vegetation period, when the plants leave started to turn yellow, they contained ascorbic acid in a considerable amount (Meos et al., 2017). The yellow color of the flowers indicates carotenoids accumulation. The major carotenoids detected in the yellow flowers of Primula veris are (9Z)-violaxanthin, (all-E)-violaxanthin, lutein, and antheraxanthin (Yamamizo et al., 2011). Scientists state that the leaves' predominant carotenoids, such as lutein and $\beta$ carotene, are essential for the photosynthesis processes (Yamamizo et al., 2011). Leaves, stalks, and flowers of cowslip contain chlorophyll $a$ and $b$. It is known that all parts of cowslip plant accumulate up to $7 \%$ (dw) mineral content (Colombo et al., 2017).

The aim of this study was to determine the influence of soil on the chemical composition of cowslip (Primula veris L.).

\section{RESEARCH METHODS}

The cowslip (Primula veris L.) leaves and inflorescences were collected in April-May of 2019 in different regions of Lithuania (area No. $1-55^{\circ} 27^{\prime} \mathrm{N}, 22^{\circ} 45^{\prime} \mathrm{E}$, area No. $2-55^{\circ} 24^{\prime} \mathrm{N}, 22^{\circ} 53^{\prime} \mathrm{E}$ ). The areas were about $10 \mathrm{~km}$ away from the main roads. The main properties of the soil plough layer presented in Table 1. Each area of the experimental plot was $3 \mathrm{~m}^{2}$. The plot was divided into three fields of $1 \mathrm{~m}^{2}$ (three replications). $1 \mathrm{~kg}$ of the cowslip leaves and inflorescences was harvested separately from each field and homogenised laboratory samples were prepared.

Table 1. The main properties of the soil plough layer

\begin{tabular}{|l|c|c|c|c|c|} 
& $\mathrm{pH}$ KCl & $\begin{array}{c}\text { Available } \\
\text { phosphorus }\left(\mathrm{P}_{2} \mathrm{O}_{5}\right) \\
\mathrm{mg} \mathrm{kg}^{-1}\end{array}$ & $\begin{array}{c}\text { Available } \\
\text { potassium }\left(\mathrm{K}_{2} \mathrm{O}\right) \\
\mathrm{mg} \mathrm{kg}^{-1}\end{array}$ & $\begin{array}{c}\text { Total nitrogen (N) } \\
\mathrm{mg} \mathrm{kg}^{-1}\end{array}$ & $\begin{array}{c}\text { Available iron } \\
(\mathrm{Fe}) \\
\mathrm{mg} \mathrm{kg}^{-1}\end{array}$ \\
\hline Area No. 1 & 6.4 & 47 & 75 & 0.12 & 1206 \\
\hline Area No. 2 & 6.9 & 184 & 168 & 0.08 & 1476 \\
\hline
\end{tabular}

Chemicals used in this study were of analytical grade. Chemical analyses were performed in three replications.

The soil $\mathrm{pH}_{\mathrm{KCl}}$ was measured in $1 \mathrm{~N} \mathrm{KCl}$ extraction by potentiometric method (ISO 10390); available phosphorus $\left(\mathrm{P}_{2} \mathrm{O}_{5}\right.$ ) and available potassium $\left(\mathrm{K}_{2} \mathrm{O}\right)$ were measured by the Egner-Riehm-Domingo (A-L) method (Egner et al., 1960). Total nitrogen content in the soil samples was determined by the Kjeldalh method (ISO 11261). Available iron (Fe) was established by inductively coupled plasma atomic emission spectrometry (ICP-AES).

Determination of chemical composition was based on the use of fresh leaves and inflorescences of cowslips. The leaves and inflorescences were analysed immediately after harvesting.

Dry matter content was assessed by drying the leaves and inflorescences samples to constant mass at $105^{\circ} \mathrm{C}$ (AOAC, 2016); soluble solids concentration was measured in the juice pressed from homogenised cowslip leaves and inflorescences by using a digital refractometer PAL-1 (Atago, Japan) at $20^{\circ} \mathrm{C}$ (AOAC, 2016). Ascorbic acid content was determined by titration with 2,6-dichlorphenol-326 indophenol sodium salt dehydrate (AOAC, 2016). Titratable acidity was determined by titration with $0,1 \mathrm{~N}$ sodium hydroxide solution to the definite pink endpoint and expressed as \% of citric acid (AOAC, 2016). Total carotenoid content, chlorophyll $a$ and chlorophyll $b$ were analysed by using a two-ray UVS-2800 spectrophotometer (Labomed Inc., USA). The absorbance was read at $662 \mathrm{~nm}$ (for chlorophyll $a$ ), $645 \mathrm{~nm}$ (for chlorophyll $b$ ), and $470 \mathrm{~nm}$ (for total carotenoids content) and the amount of pigments was calculated as described by Straumite et al. (2015). For pigment extraction, a $0.4 \mathrm{~g}$ sample of homogenised leaves and inflorescences was weighed in a conical flask, extracted with $10 \mathrm{ml}$ of $100 \%$ acetone and mixed using a magnetic stirrer (VWR, USA) for 15 minutes at $700 \mathrm{rpm}$. The supernatant was then separated and the extraction was repeated. The extraction process was done in triplicate (Straumite et al., 2015).

The total phenolic content was established in the leaves and inflorescences by using the Folin-Ciocalteu reagent. Briefly $10 \mathrm{ml}$ of ethanol (70\%) were added to a $0.25 \mathrm{~g}$ sample of homogenized leaves and inflorescences and extracted in the ultrasonic bath in the $20^{\circ} \mathrm{C}$ water for $30 \mathrm{~min}$. Then extract was centrifuged at $3000 \mathrm{rpm}$ for $30 \mathrm{~min} .0 .2 \mathrm{ml}$ of prepared extract was mixed with $1 \mathrm{ml}$ of the Folin-Ciocalteu reagent, then $0.8 \mathrm{ml}$ of sodium carbonate $(7 \%)$ was added and the mixture was completed to $5 \mathrm{ml}$ with pure water. After $60 \mathrm{~min}$. of incubation at $20^{\circ} \mathrm{C}$ in the dark, the absorbance was measured at $760 \mathrm{~nm}$ using a two-ray UVS-2800 spectrophotometer (Labomed Inc., USA). Total phenolic content was measured with the calibration curve by using gallic acid equivalent standards. The results were expressed as equivalents of gallic acid (mg GAE $\left.\mathrm{g}^{-1}\right)$ (Otles, Yalcin, 2012).

The amount of crude ash was determined by the dry burning of samples at a temperature of $500{ }^{\circ} \mathrm{C}(71 / 250 / \mathrm{EEC})$. The number of mineral elements was determined from the dry mass of the cowslip's leaves and inflorescences. Phosphorus was 
measured photometrically (71/393/EEC). Calcium content was established according to Commission Directive 71/250/EEC. The ash was treated with hydrochloric acid and the calcium precipitated as calcium oxalate. The precipitate was dissolved in sulphuric acid and the formed oxalic acid was titrated with potassium permanganate solution. The ash dissolved in hydrochloric acid, then the potassium content of the solution was determined by flame photometry (71/250/EEC). Magnesium, iron, copper, manganese, zinc and boron contents were identified by atomic absorption spectrophotometry (73/46/EEC).

Data analysis was carried out with STATISTICA version 7 software (TIBCO Software, 380 Palo Alto, CA, USA). The results were analysed by using a two-way analysis of variance (ANOVA). Fisher's Least-Significant-Difference test (LSD) was applied to the experimental results to assess significant differences between mean values at the significance level of $p<$ 0.05. Linear correlation and regression analysis were performed to determine the strength and character of the relationships between variables at a probability level of $95 \%$.

\section{RESULTS AND DISCUSSION}

Studies of cowslip (Primula veris L.) parts have shown that the highest amount of dry matter was accumulated in the inflorescences (Table 2). Statistical analysis showed significant differences between the dry matter in the inflorescences and leaves. Plants collected in area No. 1 are characterized by a higher amount of dry matter as compared to plants from area No. 2. No significant differences between soluble solids in different parts of plants collected from different areas were detected (Table 2). The obtained results of titratable acidity show differences between data from inflorescences and leaves collected in area No. 1. Inflorescences titratable acidity were 2-fold higher as compared to that in the leaves. The titratable acidity of cowslip parts collected from area No. 2 does not differ significantly.

Table 2. Chemical composition of cowslip (Primula veris L.) leaves and inflorescences (f.w.)

\begin{tabular}{|c|l|c|c|c|c|}
\hline Plant part & Area & $\begin{array}{c}\text { Dry matter, } \\
\%\end{array}$ & $\begin{array}{c}\text { Soluble solids, } \\
\%\end{array}$ & $\begin{array}{c}\text { Titratable acidity, } \\
\%\end{array}$ & $\begin{array}{c}\text { Ascorbic acid, } \\
\mathrm{mg} \mathrm{kg}^{-1}\end{array}$ \\
\hline \multirow{2}{*}{ Leaves } & No. 1 & $18.36 \mathrm{a}^{*}$ & $10.13 \mathrm{a}$ & $5.12 \mathrm{a}$ & $123.20 \mathrm{~b}$ \\
\cline { 2 - 6 } & No. 2 & $17.72 \mathrm{a}$ & $10.33 \mathrm{a}$ & $7.20 \mathrm{ab}$ & $110.64 \mathrm{a}$ \\
\hline \multirow{2}{*}{ Inflorescences } & No. 1 & $23.40 \mathrm{~b}$ & $9.93 \mathrm{a}$ & $10.60 \mathrm{~b}$ & $140.43 \mathrm{c}$ \\
\cline { 2 - 6 } & No. 2 & $22.36 \mathrm{~b}$ & $10.27 \mathrm{a}$ & $7.44 \mathrm{ab}$ & $121.64 \mathrm{~b}$ \\
\hline
\end{tabular}

*Significant differences $(p<0.05)$ in columns are marked by different letters

In aerial parts of cowslip, scientists detected ascorbic acid in relatively large quantities in flowers than that in leaves (Meos et al., 2017). Our research has obtained similar results. The analysis data show that higher content of ascorbic acid was in the inflorescences (Table 2). Plants material from area No. 1 are characterized by a higher amount of ascorbic acid as compared to plants from area No. 2. Data analysis of our investigations showed a strong positive correlation between the chemical composition of the soil area No. 1 and the amount of ascorbic acid in plants $(r=0.89)$.

Yamamizo et al. (2011) indicated that the content of carotenoids in yellow-flowered Primulacea plants flowers and leaves are different because leave carotenoids are localized in the chloroplasts, while petal carotenoids reside in the chromoplasts. In the studies, we obtained different amounts of carotenoids in different parts of the plants. Total carotenoid content in leaves was higher than in inflorescences (Table 3). The highest total carotenoid content was established in leaves of plants collected from area No. 2. However, inflorescences from area No. 1 accumulated about a 2-fold bigger number of carotenoids as compared to inflorescences from area No. 2.

Scientists found that chlorophyll $b$ predominated over chlorophyll $a$ in all cowslips flower segments (Schmitzer et al., 2017). Our results confirm this statement except for the leaves collected in area No. 2 where the chlorophyll $a$ content was higher compared to the chlorophyll $b$ content (Table 3). Chlorophyll $a$ and $b$ content in cowslip leaves we found were higher to that in the inflorescences. Plants collected from area No. 1 chlorophyll $a$ and $b$ accumulated from 1 to 2 -fold higher content.

The correlation analysis showed a very strong correlations between the chemical composition of the soil of both areas and pigments content, accordingly negative for chlorophyll $a$ content $(r=-0.99)$, and positive for carotenoids and chlorophyll $b$ content $(r=0.99)$.

Phenolic compounds conclude an important and substantial group of chemicals produced by plants as secondary metabolites. Plants synthesize them as a defence matter against stress, and various predators (Gutiérrez-Grijalva et al., 2016). The plant's phenolic composition is affected by the climate, soil, vegetative stage of the plant, harvest time, and other factors (Grevsen et al., 2008). Flavonoids are a known class of phenolic compounds that play a key role in plant interactions with abiotic and biotic environments. The high levels of various phenolic compounds present in cowslip make this plant stand out with the diversity of its biological activity. El Morchid et al. (2014) found that young leaves contained lower total concentrations and a lower number of flavonoids than flowers in plants from Albania. Our investigations showed the highest total amount of phenolics compounds in the leaves of plants collected from are No. 1 (Table 3). The researchers found that in response to light UV radiation an increased number of phenolic compounds, such as hydrolysed tannins, flavonols, and anthocyanins arise in plants (Pollastri, Tattini, 2011; Gutiérrez-Grijalva et al., 2016). In our case, the higher number of phenolics in plant leaves may have been accumulated due to the higher number of sunny days in early spring in area No 1. 
Others researchers have established that the supply of nitrogen fertilizer in the cultivation of some herbaceous plants produces more plant material and may alter the concentration of phenolic compounds in aerial parts (Grevsen et al., 2008, Besiada et al., 2009). The soil of area No. 1 was 1.5-fold higher in $\mathrm{N}$ content (Table 1), and plants from this area accumulated a higher number of total phenolics (Table 3). Data analysis of our investigations showed a very strong correlations between the chemical composition of the soil and the amount of total phenolics in plants, positive correlation for the area No. $1(r=0.99)$, and negative for the area No. $2(r=-1.00)$.

Cowslips like other wild edible plants are rich in minerals and can supply the mineral requirements of peoples. The crude ash content of the investigated cowslips was in the range from 5.91 to $11.08 \%$, which was the highest in plant leaves from area No. 2 (Table 4). The leaves accumulated $1.5-1.8$-fold more as compare to inflorescences. Plants collected from area No. 2 accrued a higher number of crude ashes.

Table 3. Chemical composition of cowslip (Primula veris L.) leaves and inflorescences (f.w.)

\begin{tabular}{|c|l|c|c|c|c|}
\hline Plant part & Area & $\begin{array}{c}\text { Total carotenoids, } \\
\mathrm{mg} \mathrm{kg}^{-1}\end{array}$ & $\begin{array}{c}\text { Chlorophyll } a, \\
\mathrm{mg} \mathrm{kg}^{-1}\end{array}$ & $\begin{array}{c}\text { Chlorophyll } b, \\
\mathrm{mg} \mathrm{kg}^{-1}\end{array}$ & $\begin{array}{c}\text { Total phenolics, } \\
\mathrm{mg} \mathrm{GAE} \mathrm{g}^{-1}\end{array}$ \\
\hline \multirow{2}{*}{ Leaves } & No. 1 & $160.29 \mathrm{~b}$ & $386.06 \mathrm{c}$ & $470.60 \mathrm{c}$ & $3.76 \mathrm{c}$ \\
\cline { 2 - 6 } & No. 2 & $181.53 \mathrm{~b}$ & $374.44 \mathrm{c}$ & $334.14 \mathrm{~b}$ & $1.41 \mathrm{a}$ \\
\hline \multirow{2}{*}{ Inflorescences } & No. 1 & $128.67 \mathrm{ab}$ & $155.59 \mathrm{~b}$ & $263.74 \mathrm{~b}$ & $1.25 \mathrm{a}$ \\
\cline { 2 - 6 } & No. 2 & $68.76 \mathrm{a}$ & $69.35 \mathrm{a}$ & $145.13 \mathrm{a}$ & $1.58 \mathrm{~b}$ \\
\hline
\end{tabular}

*Significant differences $(p<0.05)$ in columns are marked by different letters

The concentrations of four macro elements ( $\mathrm{P}, \mathrm{K}, \mathrm{Ca}, \mathrm{Mg}$ ) and five micro elements $(\mathrm{Cu}, \mathrm{Zn}, \mathrm{B}, \mathrm{Mn}, \mathrm{Fe})$ in cowslip leaves and inflorescences were established. According to researchers, the highest amount in Primula auriculata plants was found of potassium (K) for about $1.10 \%$ (Kibar, Temel, 2015). The plants we studied were richer in potassium even several times (Table 4). Potassium content in plants from different areas was similar, only in parts of the plant were distributed differently. In leaves of plants from area No. 1 and inflorescences from area No. 2 potassium content was higher. The differences could form from the K availability in the particular soils (Chizzola, 2012). Similar tendencies in our investigated plants were observed with calcium $(\mathrm{Ca})$ and magnesium $(\mathrm{Mg})$ content (Table 4). Phosphorus $(\mathrm{P})$ content in plants leaves were higher as compared to inflorescences.

Correlation analysis showed very strong negative relation between soil chemical composition and phosphorus content in plants from both areas (accordingly $r=-0.94$ for area No. $1, r=-0.99$ for area No. 2). The obtained correlations between the chemical composition of the soil and the amount of $\mathrm{K}, \mathrm{Ca}$, and $\mathrm{Mg}$ accumulated in the plants were very strong but opposite to the different areas, negative correlation for the area No. 1 (accordingly $r=-0.99, r=-0.98, r=-0.97$ ), and positive for the area No. 2 ( $r=0.99$ in all cases).

Table 4. Crude ash and macro elements of cowslip (Primula veris L.) leaves and inflorescences, \% (d.m.)

\begin{tabular}{|c|l|c|c|c|c|c|}
\hline Plant part & Area & Crude ash & P & K & Ca & Mg \\
\hline \multirow{2}{*}{ Leaves } & No. 1 & $10.92 \mathrm{~b}$ & $0.30 \mathrm{~b}$ & $3.75 \mathrm{c}$ & $0.90 \mathrm{~b}$ & $0.29 \mathrm{c}$ \\
\cline { 2 - 7 } & No. 2 & $11.08 \mathrm{~b}$ & $0.55 \mathrm{c}$ & $2.29 \mathrm{~b}$ & $0.38 \mathrm{a}$ & $0.21 \mathrm{~b}$ \\
\hline \multirow{2}{*}{ Inflorescences } & No. 1 & $5.91 \mathrm{a}$ & $0.23 \mathrm{a}$ & $1.46 \mathrm{a}$ & $0.40 \mathrm{a}$ & $0.17 \mathrm{a}$ \\
\cline { 2 - 7 } & No. 2 & $7.52 \mathrm{ab}$ & $0.29 \mathrm{~b}$ & $3.48 \mathrm{c}$ & $0.91 \mathrm{~b}$ & $0.36 \mathrm{~d}$ \\
\hline
\end{tabular}

$*$ Significant differences $(p<0.05)$ in columns are marked by different letters

The micro elements $(\mathrm{Cu}, \mathrm{Zn}, \mathrm{B}, \mathrm{Mn}, \mathrm{Fe})$ contained in cowslip leaves and inflorescences showed a wide variability. Iron $(\mathrm{Fe})$ is the mineral element present in large amount followed by manganese ( $\mathrm{Mn})$, zinc $(\mathrm{Zn})$, boron (B) and copper $(\mathrm{Cu})$. Scientists stated that due to association of the Fe with photosynthesis processes, the leaves display higher contents of this mineral element than other plant parts (Chizzola, 2012). Our results confirm this statement. Leaves of cowslips from both areas accumulated a significantly bigger amount of this mineral element as compare to inflorescences (Table 5). It was found that the total amount of Fe in plants from area No. 2 was higher. According to scientists (Radman et al., 2015), the high content of iron and potassium in plants can be the result of high levels of these minerals in the soil. Our results are similar. The soil of the area No. 2 was found of almost 2-fold higher mobile potassium, and 1.2-fold higher mobile iron content (Table 1). Researchers indicates, that Mn levels in medicinal leaves range from 20 to $300 \mathrm{mg} \mathrm{kg}^{-1}$ (Chizzola, 2012). The highest Mn content in our investigated cowslips was established in plant inflorescences from area No. 1 (Table 5). Higher average amounts of $\mathrm{Cu}$ and $\mathrm{Zn}$ were accumulated by plants from area No. 2, and the highest amounts were found in plants leaves from this area (Table 5). According to researchers, the sufficient or normal range of $\mathrm{Cu}$ in plants is from 5 to $20 \mathrm{mg} \mathrm{kg}^{-1}$ that is required for growth (Chizzola, 2012). Concentrations exceed $30 \mathrm{mg} \mathrm{kg}^{-1}$ may refer to $\mathrm{Cu}$ toxicity symptoms. In our investigated cowslips parts $\mathrm{Cu}$ content ranged from 5.30 to $14.70 \mathrm{mg} \mathrm{kg}^{-1}$ (Table 5). According to Chizzola (2012), the Zn concentration in medicinal plants leaves are between 25 and $150 \mathrm{mg} \mathrm{kg}^{-1}$. Zn content in analyzed cowslips ranged from 14.80 to $35.10 \mathrm{mg} \mathrm{kg}^{-1}$ (Table 5). Our investigations showed different amounts of B in plants parts from different areas, but a bigger average amount of B was established in plants from area No. 1 (Table 5). 
Table 5. Micro element of cowslip (Primula veris L.) leaves and inflorescences, $\mathrm{mg} \mathrm{kg}^{-1}$ (d.m.)

\begin{tabular}{|c|l|c|c|c|c|c|}
\hline Plant part & Area & $\mathrm{Cu}$ & $\mathrm{Zn}$ & $\mathrm{B}$ & $\mathrm{Mn}$ & $\mathrm{Fe}$ \\
\hline \multirow{2}{*}{ Leaves } & No. 1 & $5.30 \mathrm{a}$ & $14.80 \mathrm{a}$ & $19.60 \mathrm{c}$ & $36.70 \mathrm{a}$ & $142.30 \mathrm{c}$ \\
\cline { 2 - 7 } & No. 2 & $14.70 \mathrm{c}$ & $35.10 \mathrm{~d}$ & $17.40 \mathrm{~b}$ & $67.50 \mathrm{~b}$ & $249.30 \mathrm{~d}$ \\
\hline \multirow{2}{*}{ Inflorescences } & No. 1 & $9.35 \mathrm{~b}$ & $18.00 \mathrm{c}$ & $13.00 \mathrm{a}$ & $167.00 \mathrm{c}$ & $121.70 \mathrm{~b}$ \\
\cline { 2 - 7 } & No. 2 & $5.70 \mathrm{a}$ & $16.80 \mathrm{~b}$ & $23.90 \mathrm{~d}$ & $43.30 \mathrm{a}$ & $71.60 \mathrm{a}$ \\
\hline
\end{tabular}

$*$ Significant differences $(p<0.05)$ in columns are marked by different letters

The correlation analysis between the chemical composition of the soil and the amount of $\mathrm{Fe}, \mathrm{Mn}, \mathrm{Cu}, \mathrm{Zn}$ and $\mathrm{B}$ accumulated in the plants showed very strong relations but opposite to the different areas, accordingly positive for Fe and B content in plants from the area No. 2 ( $r=0.99$ in both cases), and negative for plant from the area No. 1 ( $r=-0.99$ and $r=-$ $0.97)$, positive for $\mathrm{Cu}(r=0.99), \mathrm{Mn}(r=1.00)$, and $\mathrm{Zn}(r=0.94)$ content in plants from the area No. 1 , and negative in plants from the area No. 2 ( $r=-0.99$ in all cases).

\section{CONCLUSIONS}

Our research showed the different chemical compositions of wild growth cowslip (Primula veris L.) collected from different areas. Higher amounts of dry matter, ascorbic acid, chlorophyll $a$ and $b$, total carotenoids, and total phenolics were found in the plants from area No. 1. The soil of this area contained 1.5-fold higher total nitrogen content compared to area No. 2. Higher nitrogen content in the soil may have affected the chemical composition of the plants. In the plant's leaves and inflorescences from area No. 2 were established higher content of crude ash, although the amounts of individual mineral elements varied unequally. The soil of area No. 2 was found of almost 4-fold higher mobile phosphorus, 2-fold higher mobile potassium, and 1.2-fold higher mobile iron content. The correlations showed the dependence of the chemical composition of cowslip (Primula veris L.) aerial parts on the soil composition.

\section{REFERENCES}

1. Assessment report on Primula veris L. and/or Primula elatior (L.) Hill, flos. 2013. European Medicines Agency, pp. 1 - 14. Available at: https://www.ema.europa.eu/en/documents/herbal-report/final-assessment-report-primula-veris-1/primula-elatior-l-hill-flos_en.pdf

2. Bączek K., Przybył J.L., Mirgos M., Kosakowska O., Szymborska-Sandhu I., Węglarz Z. 2017. Phenolics in Primula veris L. and Primula elatior (L.) Hill Raw Materials. International Journal of Analytical Chemistry, Vol. $7, \quad$ pp. $1 \quad-\quad 8$. https://doi.org/10.1155/2017/2871579

3. Biesiada A., Woloszczak E., Sokól-Lêtowska A., Kurcharska A.Z., Nawirska-Olszanska A. 2009. The effect of nitrogen form and dose on yield, chemical composition and antioxidant activity of stinging Nettle (Urtica dioica L.). Herba Polonica, Vol. 55 , pp. 84 - 93.

4. Brys R., Jacquemyn H. 2009. Biological Flora of the British Isles: Primula veris L. Journal of Ecology, Vol. 97 , pp. $581-600$. https://doi.org/10.1111/j.1365-2745.2009.01495.x

5. Chizzola R. 2012. Metallic mineral elements and heavy metals in medicinal plants. Medicinal and Aromatic Plant Science and Biotechnology, Vol. 6, pp. $39-53$.

6. Colombo P.S., Flamini G., Rodondi G., Giuliani C., Santagostini L., Fico G. 2017. Phytochemistry of European Primula species. Phytochemistry, Vol. 143, pp. 132 - 144. https://doi.org/10.1016/j.phytochem.2017.07.005

7. Égnér H., Riehm H., Domingo W.R. 1960. Untersuchungen uber die chemische Bodenanalyse als Grundlage fur die Beurteilung des Nahrstoffzustandes der Boden, II: Chemische Extraktionsmethoden zur Phosphor, und Kalium-bestimmung. Kungliga Lantbrukshogskolans Annaler, Vol. 26, pp. 199 - 215.

8. El Morchid, El. M., Torres Londoño P., Papagiannopoulos,M., Gobbo-Neto,L., Müller,C. 2014. Variation in flavonoid pattern in leaves and flowers of Primula veris of different origin and impact of UV-B. Biochemical Systematics and Ecology, Vol. 53 , pp. 81 - 88. https://doi.org/10.1016/i.bse.2013.12.032

9. First Commission Directive of 15 June 1971 establishing Community methods of analysis for the official control of feeding-stuffs (71/250/EEC), 1-22. Available at: http://data.europa.eu/eli/dir/1971/250/2005-02-16 .

10. Fourth Commission Directive of 5 December 1972 establishing Community methods of analysis for the official control of feedingstuffs (73/46/EEC), 1-7. Available at: http://data.europa.eu/eli/dir/1973/46/1999-05-26

11. Grevsen K., Frette X.C., Christensen L.P. 2008. Concentration and composition of flavonol glycosides and phenolic acids in aerial parts of Stinging Nettle (Urtica dioica L.) are affected by nitrogen fertilization and by harvest time. European Journal of Horticultural Sciences, Vol. 73, pp. $20-27$.

12. Guggisberg, A., Mansion, G., Kelso, S., Conti E. 2006. Evolution of biogeographic patterns, ploidy levels, and breeding systems in a diploid-polyploid species complex of Primula. New Phytologist, 171, pp. 617 - 632. https://doi.org/10.1111/j.1469-8137.2006.01722.x

13. Gutiérrez-Grijalva E.P., Ambriz-Pére D.L., Leyva-López N., Castillo-López R.I., Heredia J.B. 2016. Review: dietary phenolic compounds, health benefits and bioaccessibility. Archivos Latinoamericanos de Nutricion, Vol. 66, pp. 87 - 100.

14. Hill M.O., Preston C.D., Roy D.B. 2004. PLANTATT. Attributes of British and Irish Plants: Status, Size, Life History, Geography and Habitats. Centre for Ecology and Hydrology, Monks Wood, Cambridgeshire. 
15. ISO 10390. Soil Quality - Determination of pH, International Organization for Standardization: Geneva, Switzerland, 2005 ; pp. 5.

16. ISO 11261. Soil Quality - Detrmination of Total Nitrogen - Modified Kjeldahl Method. International Organization for Standardization: Geneva, Switzerland, 1995; pp. 4.

17. Kibar B., Temel S. 2015. Edible plants growing in the eastern Anatolia region grasslands of Turkey and consumed as vegetables. Journal of Food Processing and Preservation, Vol. 40, pp. 56 - 66. https://doi.org/10.1111/jfpp.12583

18. Meos A., Zaharova I., Kask M., Raal A. 2017. Content of Ascorbic Acid in Common Cowslip (Primula veris L.) Compared to Common Food Plants and Orange Juices. Acta Biologica Cracoviensia, Vol. 59, pp. 113 - 120. https://doi.org/10.1515/abcsb-2016-0020

19. Official methods of analysis of AOAC International - 20t $\mathrm{t}^{\mathrm{h}}$ edition, Latimer G.W. Jr., Eds.; AOAC International, Rockville, USA, 2016.

20. Otles S., Yalcin B. 2012. Phenolic Compounds Analysis of Root, Stalk, and Leaves of Nettle. The Scientific World Journal, Vol. 2012, pp. 1 - 12. https://doi.org/10.1100/2012/564367

21. Radman S., Žutić I., Fabek S., Žlabur J. Š., Benko B., Toth N., Čoga L. 2015. Influence of nitrogen fertilization on chemical composition of cultivated nettle. Emirates Journal of Food and Agriculture, Vol. 27, pp. 889 - 896. https://doi.org/10.9755/ejfa.2015-04-089

22. Schmitzer V., Mikulic-Petkovsek M., Stampar F., Cunja V. 2017. Phenolic Accumulation in Hybrid Primrose and Pigment Distribution in Different Flower Segments. Journal of American Society for Horticultural Science, Vol. $142, \quad$ pp. $192-199$. https://doi.org/10.21273/JASHS04038-17

23. Second Commission Directive of 18 November 1971 establishing Community methods of analysis for the official control of feedingstuffs (71/393/EEC), 1-12. Available at: http://data.europa.eu/eli/dir/1971/393/1998-10-09.

24. Shostak L.G., Marchyshyn S.M., Kozachok S.S., Karbovska R.V. 2016. Investigation of phenolic compounds of Primula veris L. Journal of Education, Health and Sport, Vol. 6, pp. $424-432$.

25. Straumite E., Kruma Z., Galoburda, R. 2015. Pigments in mint leaves and stems. Agronomy Research, 13 , pp. $1104-1111$.

26. Yamamizo C., Hirshima M., Kishimoto S., Ohmiya A. 2011. Carotenoid Composition in the Yellow and Pale Green Petals of Primula Species. Bulletin of the National Institute of Floricultural Science, Vol. 11, pp. 67 - 72. 